\title{
Ankyloglossia in breastfeeding infants. An update
}

\author{
Marta Costa-Romero, M.D. ., , Blanca Espinola-Docio, B.S. ${ }^{b, c}$, José M. Paricio-Talayero, \\ M.D. ${ }^{d}$ and N. Marta Díaz-Gómez, M.D. b,e
}

\section{ABSTRACT}

Short frenulum, or ankyloglossia, may lead to breastfeeding problems, with an impact on infant development, nipple damage, and early abandonment of breastfeeding.

There are currently no homogeneous diagnostic criteria, thus leading to both overdiagnosis and underdiagnosis and associated clinical consequences. The challenge to approach this condition lies in establishing whether it is a normal anatomical variation or a lingual frenulum without a functional impact and when breastfeeding difficulties which are typically attributed to it are actually caused by the frenulum.

a. Division of Neonatology, Hospital Universitario de Cabueñes, Gijón, Spain.

b. Spanish Association for Breastfeeding Promotion and Support (Asociación Española de Promoción y Apoyo a la Lactancia Materna, AELAMA).

c. Centro de Salud Luis Vives, Alcalá de Henares, Spain.

d. Association for Breastfeeding Promotion and Research (Asociación para la Promoción e Investigación de la Lactancia Materna, APILAM).

e. School of Health Sciences, Universidad de La Laguna, Tenerife, Spain.

E-mail address:

N. Marta Díaz-Gómez, M.D.:

nmdiaz@ull.edu.es

Funding:

None.

Conflict of interest: None.

Received: 2-16-2021

Accepted: 6-11-2021

\section{INTRODUCTION}

The lingual frenulum is an embryological remnant of the tissue that, during the fetal period, attaches the underside of the tongue to the floor of the mouth. Subsequently, it is almost totally reabsorbed, and a vertical fold of mucous membrane remains between the midline of the anterior part of the tongue and the floor of the mouth. Its main function is to maintain the lips and tongue in harmony with facial bones during fetal growth. Then, the frenulum prevents the tongue from making excessive movements (absence of lingual frenulum). The complete absence of frenulum is seen in some syndromes, such as Ehlers-Danlos syndrome. ${ }^{1}$

The term ankyloglossia (agkylos glossa, meaning "anchored tongue") is not a synonym of lingual frenulum, but of short frenulum. This is a congenital anomaly characterized by an abnormally short lingual frenulum that may restrict tongue mobility to certain extent, depending on its length, elasticity, and point of insertion. ${ }^{2}$ Ultrasound studies have demonstrated that such alteration in tongue mobility leads to ineffective nipple latching. ${ }^{3}$

Ankyloglossia may be sporadic or familial, and may be part of rare syndromes, such as Moebius syndrome, Beckwith-Wiedemann syndrome, orofaciodigital syndrome, and X-linked cleft palate. It is believed that cases of both isolated ankyloglossia and in association with a syndrome share a genetic component. ${ }^{1}$

Ankyloglossia has been typically associated with speech problems and, only more recently, with breastfeeding 
problems. Since the Journal of Human Lactation published a special issue on ankyloglossia in 1990 warning about its potential impact on breastfeeding, ${ }^{4}$ the number of publications about this topic has increased dramatically (Figure 1); most of these provide little scientific evidence. Out of more than 500 articles found, only 8 were randomized clinical trials (RCTs): 5 assessed the results of breastfeeding in the short term and 3 analyzed the procedural technique.

\section{PREVALENCE}

Ankyloglossia is more frequent among boys, in a ratio of 1.5-2:1.,4-6 According to the different publications, its prevalence ranges from $0.1 \%$ to $12 \% .1,25-9$ Such variation is possibly due to the lack of consensus in diagnostic criteria. ${ }^{7}$

Comparing the current frequency of ankyloglossia diagnosis to that from $10-20$ years ago, it has shown a relevant increase, probably in relation to the growing concern about its impact on breastfeeding. ${ }^{7}$ Actually, ankyloglossia is the second leading topic of discussion in online breastfeeding forums. ${ }^{10}$

\section{DIAGNOSIS}

Certain guiding signs and symptoms lead to suspect short frenulum. The presence of 1 or more of the manifestations described in Table 1 indicates the exploration of the baby's mouth, the nipples, and the breastfeeding technique.

For diagnosis, it is critical to combine the morphological identification of a short frenulum and the functional aspects of the tongue because some cases initially considered severe have little clinical impact, while other apparently milder cases involve major breastfeeding problems. The explanation to this is that sucking is a complex mechanism involving other mouth components in addition to the tongue. ${ }^{3}$

FIGURE 1. Articles about ankyloglossia published in PubMed between 1950 and 2019, approaching the subject from an overall perspective and in relation to breastfeeding

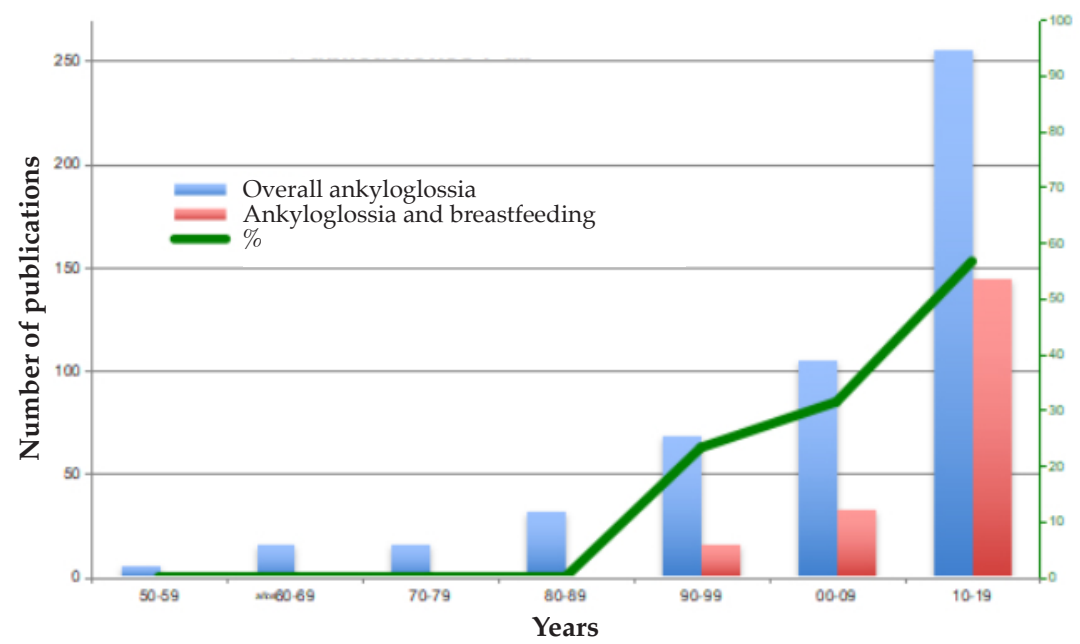

TABLE 1. Signs and symptoms of suspected ankyloglossia $a^{1,3,6,14,18}$

\begin{tabular}{ll} 
Latching difficulty & Callus from breastfeeding \\
Painful and / or cracked nipple & Facial asymmetry \\
Prolonged or very frequent feeds & Twisted mouth when opened \\
The tongue cannot extend beyond the lip & The tongue remains down during crying \\
Stunting & Gothic palate \\
Recurrent mastitis & Cheek hypertrophy \\
\hline
\end{tabular}


Major controversies exist around the clinical diagnosis of short frenulum, and many diagnostic tests have been poorly validated..$^{1,11-13}$ Below, we summarize the characteristics of the most common tests.

- Coryllos assessment: ${ }^{13}$ It assesses the physical characteristics of the frenulum, its location and attachment, and classifies short frenulum into 4 types: 2 anterior (types 1 and 2) and 2 posterior (types 3 and 4) (Figure 2). Types 1 and 2 are easily recognizable, and there is an adequate inter-observer agreement. However, posterior short frenulum is problematic, especially type 4 . A wide variation is observed when comparing the percentage of diagnosis for each type in the different studies. ${ }^{2,6}$

- Hazelbaker assessment: ${ }^{11}$ It is a tedious assessment not exempt from inconveniences, such as little inter-observer agreement, attributable to its subjective items and the influence of the child's collaboration during examination (Annex). ${ }^{14}$

- Amir assessment: ${ }^{15}$ In 2006, Amir et al. reviewed the items in Hazelbaker assessment and observed that the 3 items for lingual function (tongue lateralization, lift, and extension) showed a greater diagnostic effectiveness and inter-observer agreement (Kappa index: 0.65). Based on this, the authors propose using a simplified version of the Hazelbaker assessment including only these items, with a cutoff point of 4 or less to perform a frenotomy. ${ }^{15}$

According to current evidence, there is no justification for actively looking for short frenulum during infants' routine check-ups. Ankyloglossia should only be considered a potential cause when mothers describe

FIGURE 2. Types of ankyloglossia based on Coryllos' classification ${ }^{13}$
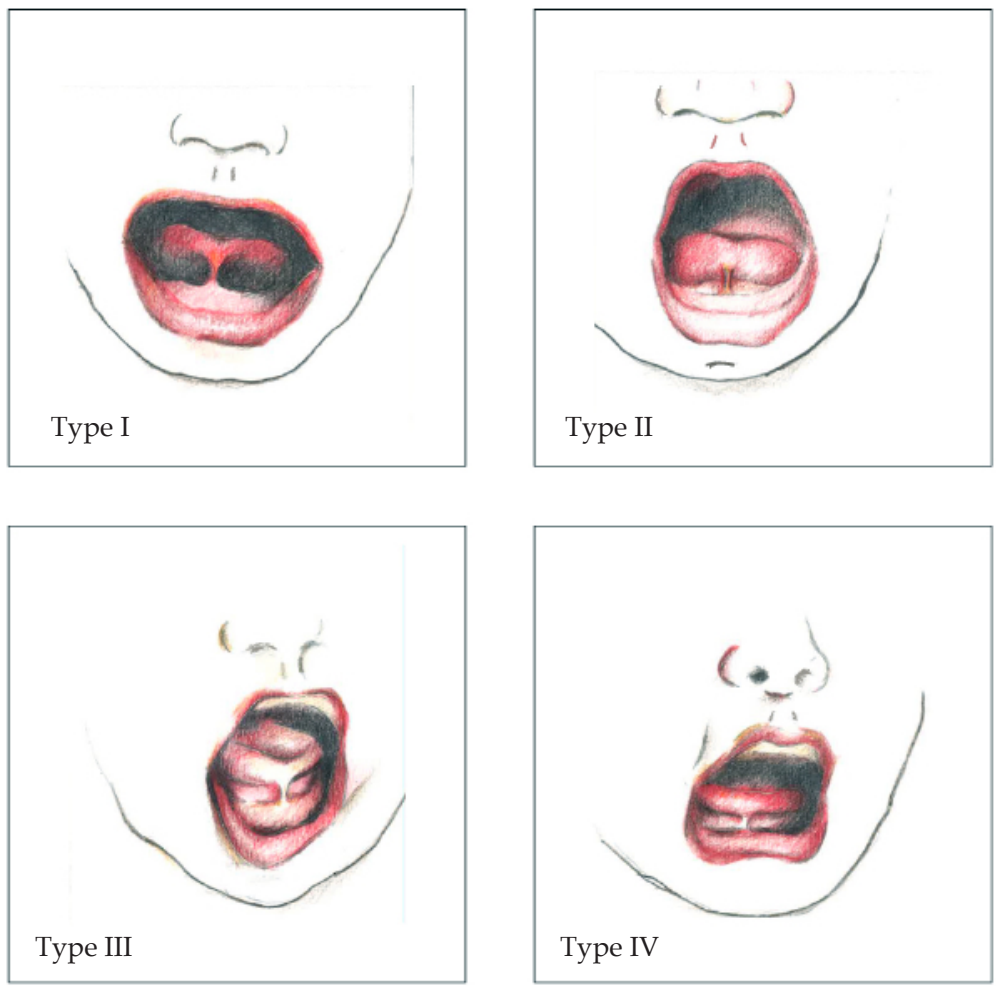

Type I: The frenulum is thin and elastic, anchored from the tip of the tongue. The tongue is heart-shaped when extended.

Type II: The frenulum is thin and elastic, and the tongue is anchored 2-4 $\mathrm{mm}$ from the tip to the floor of the mouth close to the alveolar ridge.

Type III: The frenulum is thick, fibrous and less elastic, and attached to the mid-tongue. The tongue cannot be lifted, and is shaped like a scoop when extension is attempted.

Type IV: The frenulum is not visible, but when touching the area, the examiner can feel a fibrous or submucous, thick and slightly elastic anchor, from the base of the tongue to the floor of the mouth. The tongue cannot be lifted and performs asymmetric movements when extension is attempted. 
breastfeeding problems and diagnostic tests are indicated. ${ }^{16}$

\section{CONSEQUENCES OF ANKYLOGLOSSIA}

The main consequences attributed to ankyloglossia are detailed below:

- Feeding problems: The impact on breastfeeding has been widely known and mentioned, although the proportion of infants with ankyloglossia and breastfeeding difficulties and the most common types of problems vary depending on the publication (Table 2). ${ }^{6,9,17}$

Ineffective tongue movements lead to poor sealing around the nipple and suction. The infant tries to make up for this by holding onto the nipple with the gums, thus causing pain and cracks. Increased salivation is typical. ${ }^{14}$ Milk expression is hurdled, thus reducing milk production, which affects infant development and the mother's anxiety, and may lead to early and unwanted weaning. Fortunately, many infants with moderate ankyloglossia are capable of making up for the difficulty and improve suction progressively, ${ }^{5}$ thus favoring their mother's ability to breastfeed and reducing nipple pain, without the need for a surgical procedure. 3,16,17

- Diction: Typically, short frenulum was pointed as the cause of speech problems and malocclusion. However, at present, there is no evidence confirming the association between ankyloglossia and diction problems, or that a frenotomy would prevent future problems. ${ }^{1,5}$

- Teething: A lower tongue mobility during the fetal period may determine a worse palate formation, which results in gothic palate and dental crowding. ${ }^{14}$

\section{TREATMENT}

There are currently different therapeutic approaches, both surgical and conservative. The challenge to approach this condition lies in establishing whether it is a normal anatomical variation or a frenulum without a functional impact and when breastfeeding difficulties which are typically attributed to it are actually caused by it. Therefore, the management of short lingual frenulum is still controversial.

\section{Non-surgical approach}

Approximately $50 \%$ of infants with short frenulum have no breastfeeding problems and there is no need for any treatment. ${ }^{19}$ When breastfeeding is impacted, a non-surgical approach should be started; only if breastfeeding problems persist, potential surgery should be assessed. ${ }^{20}$ Support and guidance from experts in breastfeeding are critical. It will be based on individualized sessions aimed at correcting posture during feeding and improving latch. Therefore, in many cases, breastfeeding problems resolve without the need for any intervention.

According to some authors, the above-

TABLE 2. Frequency of main signs and symptoms attributed to ankyloglossia, according to different authors

\begin{tabular}{|c|c|c|c|}
\hline \multicolumn{2}{|c|}{ Signs and symptoms } & $\begin{array}{l}\% \\
77\end{array}$ & \multirow{2}{*}{$\begin{array}{l}\text { Author } \\
\text { Griffths, 20049 } \\
\text { Riskin, 2014 } \\
\text { Wong, 2017 } \\
\text { Ballard, 2002 }\end{array}$} \\
\hline In the mother & - Painful and cracked nipple & $\begin{array}{c}77 \\
29.5 \\
60.5 \\
36.6\end{array}$ & \\
\hline & - Lower milk production & 16.4 & Riskin, $2014^{16}$ \\
\hline & - Generalized breastfeeding difficulties & $\begin{array}{c}59 \\
12.8 \\
12.44 \\
69 \\
88\end{array}$ & $\begin{array}{l}\text { Riskin, 2014 }{ }^{16} \\
\text { Ballard, 2002 } \\
\text { Emond, 2013 } \\
\text { Wong, 2017 } \\
\text { Griffths, } 2004^{9}\end{array}$ \\
\hline \multirow[t]{3}{*}{ In the infant } & - Failure to thrive & $\begin{array}{l}8.2 \\
6.8\end{array}$ & $\begin{array}{l}\text { Riskin, } 2014^{16} \\
\text { Ballard, } 2002^{6}\end{array}$ \\
\hline & - Long feedings & $\begin{array}{c}72 \\
14.4\end{array}$ & $\begin{array}{l}\text { Griffths, } 2004^{9} \\
\text { Riskin, } 2014^{16}\end{array}$ \\
\hline & - Trouble latching & $\begin{array}{c}88 \\
63.6\end{array}$ & $\begin{array}{l}\text { Griffths, } 2004^{9} \\
\text { Ballard, } 2002^{6}\end{array}$ \\
\hline
\end{tabular}


mentioned measures may be combined with orofacial myofunctional therapy, a technique involving extraoral and intraoral stimulation exercises aimed at improving rooting and sucking reflexes in newborn infants. ${ }^{21}$ This therapy is also recommended before and after frenotomy. ${ }^{21}$ For the time being, although there is no evidence regarding its effectiveness, it has been confirmed that, with support, posture and latch correction, and orofacial myofunctional therapy pain in the nipple is reduced, milk transfer improves, and mothers progressively improve their assurance in breastfeeding, without the need for surgery. ${ }^{18}$

\section{Surgical approach}

Until a few years ago, preventive frenotomies were performed to avoid cracks and/or pain and favor milk production. Currently, surgical treatment is recommended only if ankyloglossia is associated with breastfeeding problems, including painful and cracked nipples, poor latch, and little weight gain, that could not be resolved with a conservative approach. In addition, there is not enough evidence to support surgical treatment in children with other problems besides breastfeeding difficulties, such as speech problems. ${ }^{6}$

A careful, individualized assessment of each case of breastfeeding and of the risks and benefits of surgical treatment should be done before making a decision. ${ }^{14,22}$ The recommended time for surgery should also be determined with caution. Some situations make it necessary to provide an early treatment, but, in general, some time is allowed to see if conservative measures manage to resolve the problem.

\section{Types of surgical treatments Frenotomy}

It is the procedure in which the lingual frenulum is cut. It is the most common technique performed in newborns and young infants because it is a simple and fast procedure that can be done in the physician's office. ${ }^{23}$ However, the expert panel on ankyloglossia moderated by Messner ${ }^{24}$ did not reach a consensus on the ideal place to perform a frenotomy. The Academy of Breastfeeding Medicine Position Statement on Ankyloglossia ${ }^{25}$ points out that, in the case of a short frenulum with breastfeeding problems unresponsive to conservative measures, the objective should be to perform surgery in the less invasive manner possible. The upper lingual frenulum is a normal structure and should not be excised to improve breastfeeding problems. ${ }^{25}$

Most experts have proposed to perform a frenotomy in the physician's office only for newborns and infants younger than 2 months. For older patients and those who require more complex techniques (frenuloplasty), the recommendation is to perform the procedure in the operating room under general anesthesia. These measures have proven to be cost-effective. ${ }^{26}$ In a recent systematic review, ${ }^{27}$ the authors concluded that frenotomy is effective in cases of ankyloglossia with breastfeeding difficulties or a low score in the Hazelbaker assessment, and proposed a treatment algorithm defining the technique and type of anesthesia (local or general) based on the child's age.

The time of surgery is controversial. An early surgery is supported by studies like the one by Emond, ${ }^{28}$ conducted in infants with moderate ankyloglossia randomly assigned to surgery at the time of diagnosis (mean age: 11 days; range: $8-16$ days) compared to those who did not undergo surgery (control group). The mothers in the control group who had painful and cracked nipples could not go more than 5 days without seeking medical help or the need for supplementing with formula. However, other authors recommend waiting 2-3 weeks for the surgery. ${ }^{19}$ Prospective studies have confirmed that delaying surgery until after 4 weeks old has been associated with high rates of abandonment of breastfeeding. ${ }^{29}$

Frenotomy technique: The use of topical anesthesia for surgery is controversial. Sucrose $24 \%$ is recommended a few minutes before it. After the surgery, sucrose may be re-administered or the infant may be placed chest-to-chest and/ or skin-to-skin with their mother immediately. If necessary, acetaminophen may be administered..$^{20}$

To perform the frenotomy, the infant may be wrapped in a blanket and held firmly, with the head towards the physician. An assistant keeps the infant's mouth open by gently pulling down their chin. The physician lifts the tongue to visualize the frenulum using a grooved director or their fingers. An incision of approximately $2 \mathrm{~mm}$ in the central mucous membrane is made using Iris scissors, with special care not to damage the base of the tongue, due to its vascularization, or the Wharton duct. ${ }^{14,30}$ The index finger may be used to push the incision area and broaden it. ${ }^{20}$

The lingual frenulum is thin and has few blood vessels, so there is little bleeding after the incision is made, ${ }^{23,30}$ and hemostasis is achieved 
by applying pressure with gauze. ${ }^{1}$ Feeding may be resumed immediately ${ }^{6,30}$ and the patient may be discharged 30 minutes after the procedure. ${ }^{30}$

Several studies have demonstrated an immediate subjective improvement, with a marked reduction in discomfort, although sometimes improvement is seen several days later. ${ }^{16,31}$

Complications of frenotomy: the rate of complications is approximately $9 \% .{ }^{14,30}$ The most common complications include bleeding (3-5\%, depending on the series), recurrence (5\%), injury in the lips or salivary glands, infections, injury in the lingual nerve, formation of mucous retention cyst, pain, and failure of technique to improve breastfeeding. ${ }^{1,30} \mathrm{~A}$ less frequent, but more severe complication is an injury in the Wharton duct. Therefore, it is important that the procedure is performed by a trained provider. ${ }^{19}$

In special cases, craniofacial abnormalities are developed, such as Pierre Robin syndrome, for which surgery should not be considered because frenotomy may favor airway obstruction with the tongue following the procedure.

To prevent recurrence, some authors advise parents to firmly push upward the incision area in the frenulum using their index finger several times a day, for the first week after the procedure. ${ }^{20}$

Frenotomy outcomes: In recent years, multiple studies about frenotomy have been published, and outcomes have been controversial. Most RCTs, which used clinical assessment scales for breastfeeding (mainly the LATCH scale, which assesses latch, audible swallowing, nipple type, comfort, and the amount of help the mother needs to hold the infant to the breast) and maternal pain scales, have demonstrated an improvement in breastfeeding ${ }^{32}$ and a significant reduction in maternal pain after the procedure. ${ }^{33}$ However, in studies that demonstrated the benefit of frenotomy, it is difficult to measure the placebo effect. ${ }^{19} \mathrm{~A}$ double-blind RCT reported that latch improved by $75 \%$ in cases that underwent the procedure, but also by $47 \%$ in the group that did not have a frenotomy. ${ }^{34}$ An observational, prospective study conducted in 264 infants who underwent a frenotomy due to breastfeeding problems found that, although most mothers $(75 \%)$ described an improvement in breastfeeding 2 weeks after the procedure, $3 \%$ stated that it had worsened. ${ }^{35}$

Some authors have corroborated a significant increase in milk production after the frenotomy ${ }^{32,36}$ and a relevant improvement in assurance and self- confidence, as assessed with the Breastfeeding Self-Efficacy Scale-Short Form (BSES-SF). ${ }^{37}$

Ultrasound studies have demonstrated that the frenotomy favors tongue release, with better mobility and lower nipple deformity. This fact translates clinically into reduced snapback and interruptions during feeding and improved sleep. A greater milk production, with less pain during the feed, and a reduction in hiccups, regurgitation, and cough immediately after the feed have also been observed..$^{36}$

A recent study based on interviews with families of infants who underwent a frenotomy confirmed a significant reduction in feeding duration and maternal pain. Among surveyed families, 97\% indicated that, in similar situations, they would choose the procedure again. ${ }^{31}$

A recent systematic review about the outcomes of frenotomy in children younger than 3 months concluded that the procedure was not associated with severe complications and that it reduced nipple pain, but none of the analyzed studies demonstrated whether it led to successful breastfeeding. The authors of that systematic review indicated that all studies had serious methodological deficiencies, so further RCTs of a high methodological quality are required to determine frenotomy effectiveness. ${ }^{8}$

\section{Frenuloplasty}

It is the complete removal of the frenulum. It is a more invasive and more difficult procedure than a frenotomy, so it should be carried out by a qualified health care provider. It is performed under general anesthesia or with anesthesia of lingual nerve. The conventional procedure is done using a scalpel and with the help of a grooved director or forceps to guide the incision. It requires sutures. ${ }^{1}$

In recent years, laser surgery has emerged as an alternative. Its main advantages are a reduction in local anesthesia use and postoperative complications (bleeding, pain, swelling, and infection) and the absence of sutures. ${ }^{23}$

As what has been recommended after a frenotomy, several authors suggest that, after a frenuloplasty, parents should run their finger along the "diamond" shape at the base of the tongue several times a day to prevent tissue scarring from reducing achieved mobility. ${ }^{1}$ After a frenuloplasty, tongue mobility exercises are recommended, such as massaging the tongue undersurface with the fingers. ${ }^{14}$

It is critical to continue supporting breastfeeding ${ }^{37}$ and, sometimes, speech therapy may be necessary to improve tongue mobility and 
speech articulation. ${ }^{14,23}$

In general, studies comparing different surgical techniques and those comparing frenotomy to non-surgical measures include varying diagnostic criteria, have little power, and do not allow to draw definite conclusions. ${ }^{1}$

\section{CONCLUSIONS}

The presence of short frenulum in newborns is considered a warning sign for potential breastfeeding difficulties. It is important to assess feedings in detail using validated scales and offer support from experts. Most cases correspond to types that do not cause problems or that can be easily resolved.

In the event of more relevant difficulties, the case should be carefully assessed to establish to what extent they are caused by the short frenulum and guidance on strategies to help with latch and support to maintain breastfeeding should be offered as an initial measure. Surgery may be useful in selected cases that fail to improve with the above-mentioned measures.

\section{Acknowledgments}

The authors would like to thank Dion Blake for the drawings made to represent the types of ankyloglossia.

\section{REFERENCES}

1. WalshJ, TunkelD. Diagnosis and treatment of ankyloglossia in newborns and infants. A review. JAMA Otolaryngol Head Neck Surg. 2017; 143(10):1032-9.

2. González Jiménez D, Costa Romero M, Riaño Galán I, González Martínez MT, et al. Prevalencia de anquiloglosia en recién nacidos en el Principado de Asturias. An Pediatr (Barc). 2014; 81(2):115-9.

3. Geddes DT, KentJC, McClellanHL, Garbin CP, et al.Sucking characteristics of successfully breastfeeding infants with ankyloglossia: a case series. Acta Pædiatrica. 2010;99(2):301-3.

4. Auerbach KG. Our first thematic issue: Ankyloglossia in Infancy. J Hum Lact. 1990; 6(3):101-2.

5. Hong P. Five things to know about...ankyloglossia (tonguetie). CMAJ. 2013; 185(2):E128.

6. Ballard JL, Auer CE, Khoury JC. Ankyloglossia: assessment, incidence, and effect of frenuloplasty on the breastfeeding dyad. Pediatrics. 2002; 110(5):e63.

7. Hazelbaker AK, Baeza C, Watson Genna C, Murphy J, et al. Incidence and Prevalence of Tongue-Tie. Clin Lact. 2017; 8(3):89-92.

8. O'Shea JE, Foster JP, O'Donnell CP, Breathnach D, et al. Frenotomy for tongue-tie in newborn infants. Cochrane Database Syst Rev. 2017; 3(3):CD011065.

9. Griffiths DM. Do tongue ties affect breastfeeding? J Hum Lact. 2004; 20(4):409-14.

10. Wong K, Patel P, Cohen MB, Levi J. Breastfeeding Infants with ankyloglossia: Insight into mothers' experiences. Breastfeed Med. 2017; 12:86-90.

11. Hazelbaker A. The Assessment tool for lingual frenulum function (ATLFF): use in a lactation consultant private practice. [Dissertation]. Pasadena, CA: Pacific Oaks College; 1993.

12. Lopes de Castro Martinelli R, Queiroz Marchesan I, BerretinFelix G. Lingual frenulum protocol for infants. Int J Orofacial Myology. 2012; 38:104-12.

13. Coryllos E, Watson Genna C, Salloum AC. Congenital tongue-tie and its impact on breastfeeding. Breastfeeding: Best for baby and mother. 2004; Summer:1-11.

14. Cuestas G, Demarchi V, Martínez Corvalán MP, Razetti J, Boccio C. Tratamiento quirúrgico del frenillo lingual corto en niños. Arch Argent Pediatr. 2014; 112(6):567-70.

15. Amir LH, James JP, DonathSM. Reliability of the Hazelbaker assessment tool for lingual frenulum function. Int Breastfeed J. 2006; 1(1):3.

16. Hall DM, Rendrew MJ. Tongue tie. Arch Dis Child. 2005; 90(12):1211-5.

17. Riskin A, Mansovsky M, Coler-Botzer T, Kugelman A, et al. Tongue-tie and breastfeeding in newborns-mothers' perspective. Breastfeed Med. 2014; 9(9):430-7.

18. Douglas P. Making sense of studies that claim benefits of frenotomy in the absence of classic tongue tie. J Hum Lact. 2017; 33(3):519-23.

19. Power RF, Murphy JF. Tongue-tie and frenotomy in infants with breastfeeding difficulties: achieving a balance. Arch Dis Child. 2015; 100(5):489-94.

20. Kenny-Scherber AC, Newman J. Office-based frenotomy for ankyloglossia and problematic breastfeeding. Can Fam Physician. 2016; 62(7):570-1. Principio del formulario. Final del formulario.

21. Zaghi S, Valcu-Pinkerton S, Jabara M, Norouz-Knutsen L, et al. Lingual frenuloplasty with myofunctional therapy: Exploring safety and efficacy in 348 cases. Laryngoscope Investig Otolaryngol. 2019; 4(5):489-96.

22. Douglas P, Geddes D. Practice-based interpretation of ultrasound studies leads the way to more effective clinical support and less pharmaceutical and surgical intervention for breastfeeding infants. Midwifery. 2018; 58:145-55.

23. Junqueira MA, Cunha NN, Silva LLC, Araújo LB, et al. Surgical techniques for the treatment of ankyloglossia in children: a case series. J Appl Oral Sci. 2014; 22(3):241-8.

24. Messner AH, Walsh J, Rosenfeld RM, Schwartz SR, et al. Clinical Consensus Statement: Ankyloglossia in Children. Otolaryngol Head Neck Surg. 2020; 162(5):597-11.

25. LeFort Y,Evans A, Livingstone V, DouglasP, etal. Academy of Breastfeeding MedicinePositionStatement on Ankyloglossia in Breastfeeding Dyads. Breastfeed Med. 2021; 16(4):278-81.

26. Toner D, Giordano T, Handler SD. Office frenotomy for neonates: resolving dysphagia, parental satisfaction and cost-effectiveness. ORL Head Neck Nurs. 2014; 32(2):6-7.

27. Shekher R, Lin L, Zhang R, Hoppe IC, et al. How to Treat a Tongue-tie: An Evidence-based Algorithm of Care. Plast Reconstr Surg Glob Open. 2021; 9(1):e3336.

28. Emond A, Ingram J, Johnson D, Blair P, et al. Randomised controlled trial of early frenotomy in breastfed infants with mild-moderate tongue-tie. Arch Dis Child Fetal Neonatal Ed. 2014; 99(3):F189-95.

29. Donati-BourneJ, BatoolZ,Hendrickse C, Bowley D. Tonguetie Assessment and division: A time-critical intervention to optimise breastfeeding. J Neonatal Surg. 2015; 4(1):3.

30. Hansen R, MacKinlay GA, Manson W. Ankyloglossia intervention in outpatients is safe: our experience. Arch Dis Child. 2006; 91(6):541-2.

31. Illing S, Minnee M, Wheeler J, Illing L. The value of frenotomy for ankyloglossia from a parental perspective. N Z Med J. 2019; 132(1500):70-81.

32. Martinelli RL, Marchesan IQ, Gusmão RJ, Honório HM et al. The effects of frenotomy on breastfeeding. J Appl Oral Sci. 2015; 23(2):153-7. 
33. Srinivasan A, Dobrich C, Mitnick H, Feldman P. Ankyloglossia in breastfeeding infants: the effect of frenotomy on maternal nipple pain and latch. Breastfeed Med. 2006; 1(4):216-24.

34. Berry J, Griffiths M, Westcott C. A double-blind, randomized, controlled trial of tongue-tie division and its immediate effect on breastfeeding. Breastfeed Med. 2012; 7(3):189-93.

35. Dollberg S, Marom R, Botzer E. Lingual frenotomy for breastfeeding difficulties: a prospective follow-up study. Breastfeed Med. 2014; 9(6):286-9.
36. Geddes DT, Langton DB, Gollow I, Jacobs L, et al. Frenulotomy for breastfeeding infants with ankyloglossia: Effect on Milk Removal and Sucking Mechanism as Imaged by Ultrasound. Pediatrics. 2008; 122(1):e188-94.

37. Ghaheri B, Cole M, Fausel S, Chuop M, Mace JC. Breastfeeding Improvement Following Tongue-Tie and Lip-Tie Release: A prospective cohort study. Laryngoscope. 2017; 127(5):1217-23.

38. Riaño I. Manejo de la lactancia materna en el lactante enfermo. In: Asociación Española de Pediatría. Manual de breastfeeding: de la teoría a la práctica. Madrid: Panamericana 2008.Pages.371-85. 


\section{ANNEX. \\ Classification of lingual frenulum based on the Hazelbaker criteria (Modified from Ballard et al. ${ }^{6}$ and Riaño ${ }^{38}$ )}

\section{Tongue appearance}

1. Appearance of tongue when lifted (observe the anterior edge of the tongue when the baby is crying or attempt to pull or lift the tongue):

2. Round.

1. Slight cleft in tip of tongue.

$0 . \quad \mathrm{V}$ - or heart-shaped.

2. Elasticity of frenulum (the frenulum is felt while the tongue is stretched):

2. Very elastic.

1. Moderately elastic.

$0 . \quad$ Little or no elasticity.

3. Length of lingual frenulum when tongue lifted (approximately, in $\mathrm{cm}$ ):

2. More than $1 \mathrm{~cm}$.

1. Approximately $1 \mathrm{~cm}$.

$0 . \quad$ Less than $1 \mathrm{~cm}$.

4. Attachment of frenulum to tongue (where it attaches to the lower side of the tongue):

2. Posterior to tip of tongue.

1. At tip.

0. Notched tip.

5. Attachment of lingual frenulum to inferior alveolar ridge (where the frenulum starts in the floor of mouth):

2. Attached to floor of mouth, well below alveolar ridge.

1. Attached just below alveolar ridge.

0. Attached at alveolar ridge.

\section{Lingual function}

1. Lateralization (the examiner traces the lower gum ridge and brushes the lateral edge of the tongue):

2. Complete.

1. Body of tongue but not tongue tip.

$0 . \quad$ None.

2. Lift of tongue (when the finger is removed from the infant's mouth, if the infant cries, then the tongue tip should lift to mid-mouth without jaw closure):

2. Tip to mid-mouth.

1. Only edges to mid-mouth.

0. Tip stays at alveolar ridge or rises to mid-mouth only with jaw closure.

3. Extension of tongue (the reflex is elicited by stimulating the lower lip downward toward the chin):

2. Tip over lower lip.

1. Tip over lower gum only.

0. Neither of above, OR anterior or mid-tongue humps.

4. Spread of anterior tongue (after first eliciting the rooting reflex and tickling the lips, before the baby starts sucking, the examiner looks for tongue extension and thinning):

2. Complete.

1. Moderate or partial.

0. None. 
5. Cupping (the tongue adapts to the examiner's finger with a hollow, cupping shape during sucking, as if the tongue hugged the finger):

2. Complete cup, entire edge.

1. Side edges only, not the tip.

$0 . \quad$ No cup.

6. Peristalsis (backward, wave-like motion that should originate at the tip of the tongue and is felt with the back of the examiner's finger):

2. Complete, anterior to posterior.

1. Partial, originating posterior to tip of tongue.

$0 . \quad$ None or reverse peristalsis.

7. Snapback (it is heard as a clucking sound when the tongue loses its grasp on the examiner's finger or the mother's breast when the infant tries to generate negative pressure):

2. None.

1. Periodic.

$0 . \quad$ Frequent or with each suck.

A score below 8 in the appearance items and below 11 in the function items is associated with breastfeeding difficulties. 